\title{
Metallic elements in exhaled breath condensate of patients with interstitial lung diseases
}

\author{
Massimo Corradi ${ }^{1}$, Olga Acampa ${ }^{2}$, Matteo Goldoni ${ }^{1,2}$, Elena Adami ${ }^{1}$, \\ Pietro Apostoli ${ }^{3}$, Giuseppe de Palma ${ }^{3}$, Alberto Pesci ${ }^{4}$ and Antonio Mutti ${ }^{1}$ \\ ${ }^{1}$ Department of Clinical Medicine, Nephrology and Health Sciences, University of Parma, Parma, Italy \\ 2 ISPESL Research Centre at the University of Parma, University of Parma, Italy \\ ${ }^{3}$ Department of Experimental and Applied Medicine, Section of Occupational Health and Industrial \\ Hygiene, University of Brescia, Brescia, Italy \\ ${ }^{4}$ Department of Preventive and Clinical Medicine, University of Milan-Bicocca, Monza, Italy \\ E-mail: massimo.corradi@unipr.it
}

Received 7 July 2009

Accepted for publication 13 November 2009

Published 2 December 2009

Online at stacks.iop.org/JBR/3/046003

\begin{abstract}
Epidemiological data support the hypothesis that environmental and occupational agents play an important role in the development of interstitial lung diseases such as idiopathic interstitial pneumonia (IIPs) and sarcoidosis. The aim of this study was to assess the elemental composition of exhaled breath condensate (EBC) in patients with interstitial lung diseases (ILDs) of unknown etiology and healthy subjects as an indirect evaluation of tissue burden, which could improve our understanding of the role of metals in the pathogenesis of ILDs. EBC was obtained from 33 healthy subjects, 22 patients with sarcoidosis, 15 patients with non-specific interstitial pneumonia (NSIP) and 19 with IIPs. Trace elements and toxic metals in the samples were measured by means of inductively coupled plasma-mass spectrometry. There are only small overall differences in the EBC levels of a number of metallic elements among patients with idiopathic pulmonary fibrosis (IPF), NSIP or sarcoidosis, and no pattern is capable of distinguishing them with a high degree of sensitivity and specificity. However, a pattern of pneumotoxic ( $\mathrm{Si}, \mathrm{Ni}$ ) and essential elements $(\mathrm{Zn}, \mathrm{Se}$ and $\mathrm{Cu}$ ) with the addition of $\mathrm{Co}$ distinguished the patients with ILDs from healthy non-smokers with relatively high degrees of sensitivity (96.4\%) and specificity (90.9\%). Assessing the elemental composition of EBC in patients with different ILDs seems to provide useful information. The non-invasiveness of the EBC method makes it suitable for patients with pulmonary diseases, although further studies are required to confirm the usefulness of this approach and to better understand the underlying pathophysiological processes.
\end{abstract}

(Some figures in this article are in colour only in the electronic version)

\section{Introduction}

Interstitial lung diseases (ILDs) are a heterogenic group of disorders characterized by inflammation and fibrosis involving the pulmonary interstitium and parenchyma $[1,2]$ in which structural alterations lead to progressive breathlessness, lung crackles and diffusely abnormal chest radiography findings $[1,3]$. Their pathogenesis is complex: each disorder has a different histopathological pattern with varying degrees of inflammation and fibrosis, typical radiographic features upon high resolution computed tomography (HRCT) scanning and a variable clinical course.

Idiopathic interstitial pneumonia (IIPs) and sarcoidosis seem to be the most frequent ILDs $[4,5]$. The most common IIPs are idiopathic pulmonary fibrosis (IPF) and non-specific interstitial pneumonia (NSIP), which can be distinguished 
from the other forms of diffuse parenchymal lung disease on the basis of clinical, radiological and pathological criteria [2]. Sarcoidosis is a systemic granulomatous disease with predilection for lung and the lymphoid system [6, 7].

The etiology of most ILDs is still unknown, but probably includes genetic factors, host susceptibility and exposure to specific environmental factors, as well as interactions between them [8, 9]. Epidemiological data support the hypothesis that environmental and occupational agents play an important role in the development of IPF and sarcoidosis [10]. There is a significant association between an increased risk of IPF and exposure to cigarette smoking, metal and wood dust, stone sand, and farming and livestock [11-16], and people employed in agriculture or by suppliers of hardware and building and gardening materials, or exposed to wood or organic dust, are at increased risk for sarcoidosis. Metal dusts and fumes, musty odors, microbial-rich environments and smoking are either occupational or environmental risk factors for sarcoidosis [10, 17, 18].

Further information about the role of metallic elements in the development of these diseases can be obtained by assessing lung metal burden. Biological samples can be collected using invasive methods such as lung biopsy (which clearly cannot be proposed for research purposes), bronchoalveolar lavage (BAL), which allows the direct sampling of material from the lower respiratory tract, or exhaled breath condensate (EBC) obtained by cooling exhaled air.

$\mathrm{EBC}$ is a biological matrix that seems to be representative of the composition of airway lining fluid and can therefore be used to assess biomarkers of exposure, effect and susceptibility in patients with lung diseases or subjects exposed to ambient pollutants [19-25]. Unlike BAL, it is also simple to collect and totally non-invasive, thus making it suitable for research studies. We have recently proposed using the elemental analysis of EBC as a means of deriving specific pulmonary levels of pneumotoxic or essential transition elements by considering exhaled metals as a quantitative estimate of the target tissue burden [21, 26].

The aim of this study was to assess the elemental composition of EBC in patients with ILDs of unknown etiology and healthy subjects as an indirect evaluation of tissue burden, which could improve our understanding of the role of metals in the pathogenesis of ILDs. We also investigated whether the EBC levels of several metals may be useful in distinguishing ILD patients from healthy subjects. Furthermore, EBC levels of transition elements could be used as biomarkers of susceptibility given their role in oxidant/antioxidant balance and the fact that oxidative stress seems to contribute to the pathophysiology of ILDs [27-29].

\section{Materials and methods}

\section{Study population}

The patients with IPF, NSIP or sarcoidosis were recruited at Parma Hospital's Outpatient Clinic of Interstitial Lung Diseases; the control group consisted of healthy non-smokers who were not occupationally exposed to metals.
The study was approved by the Ethics Committee of the University of Parma and was conducted in conformity with the Declaration of Helsinki. All of the subjects gave their informed written consent to participate.

IPF and NSIP were diagnosed on the basis of clinical, radiological and histological findings using the ATS/ERS international consensus criteria [2, 30]; sarcoidosis was diagnosed on the basis of clinical and radiological findings supported by histological evidence of non-caseating epithelioid cell granulomas [31, 32].

\section{Methods}

All of the study subjects (patients and controls) underwent the administration of a medical questionnaire, lung function tests and EBC collection.

Tobacco smoke exposure was evaluated in terms of selfreported current smoking status, with the number of cigarettes smoked per day and the number of years of smoking being recorded. Patients who had stopped smoking at least 1 year before recruitment were defined ex-smokers.

All of the subjects underwent spirometry, assessment of total lung capacity (TLC) and the measurement of singlebreath diffusing lung capacity for carbon monoxide (DLCO) using a flow-sensing spirometer and a body plethysmograph (Vmax, SensorMedics, USA) connected to a computer for data analysis.

EBC was collected using a portable condenser (TURBODECCS; Medivac, Parma, Italy) at a collecting constant temperature of $-5{ }^{\circ} \mathrm{C}$ as previously described [21]. Subjects were asked to breathe normally for $15 \mathrm{~min}$ and EBC collection was performed after at least $1 \mathrm{~h}$ of rest and all the samplings were done in the same room. EBC samples were stored at $-80{ }^{\circ} \mathrm{C}$ until transport in dry ice to the laboratory of Brescia (Italy) for analysis, where their elemental composition was determined by means of inductively coupled plasma mass spectrometry (ICP-MS; ELAN 5000, Perkin Elmer, Wellesley, MA) as previously described [21, 33]. Only the metallic elements with measurable levels in $33 \%$ of the EBC samples were recorded; the ICP-MS limit of detection (LOD) of metals was $0.005 \mu \mathrm{g} \mathrm{L}^{-1}$. The intrasubject variability is an average of $20-30 \%$ for the metals reported in this study.

\section{Statistics}

The data were statistically analysed by means of Prism 4 (GraphPad; San Diego, CA) and SPSS 16.0 software (SPSS; Chicago, IL). Non-parametric tests were used, as the data significantly deviated from normality. The groups (IPF, NSIP, sarcoidosis and controls) were compared using the KruskalWallis test followed by Dunn's test for multiple comparisons. The correlations between variables were assessed using Spearman's rank correlation. Multinomial and binary logistic regression was used to assess whether the groups were distinguishable, with group codes as the dependent variable and metal concentrations as predictors. The predicted probabilities of belonging to a group obtained using logistic regression were entered in a receiving operating curve (ROC) analysis in order to evaluate whether EBC concentrations of 
Table 1. Characteristics of study subjects.

\begin{tabular}{lllll}
\hline & IPF & NSIP & Sarcoidosis & Controls \\
\hline No of subjects (M/F) & $19(14 / 5)$ & $15(9 / 6)$ & $22(14 / 8)$ & $33(25 / 8)$ \\
Age & $68 \pm 0.78$ & $65.3 \pm 9.7$ & $53.5 \pm 13.9$ & $55 \pm 10.80$ \\
Ex/non-smokers & $13 / 6$ & $10 / 5$ & $16 / 6$ & $0 / 33$ \\
Pack/years & $24.5(16.5-38.5)$ & $26.4(15.0-42.5)$ & $16.5(5.3-20.0)$ & 0 \\
FEV 1 L & $1.93 \pm 0.8$ & $2.02 \pm 07$ & $2.7 \pm 1.5$ & $3.7 \pm 2$ \\
FEV $\%$ of predicted & $71.2 \pm 1.2$ & $71.7 \pm 0.4$ & $83.9 \pm 2.4$ & $117.3 \pm 1$ \\
FVC, L & $2.3 \pm 0.9$ & $2.6 \pm 0.9$ & $3.5 \pm 0.9$ & $4.8 \pm 0.9$ \\
FVC\% of predicted & $67.8 \pm 19.2$ & $80.8 \pm 18.1$ & $94 \pm 12.5$ & $108 \pm 10.5$ \\
TLC, L & $3.8 \pm 1.2$ & $4.4 \pm 1.4$ & $5.4 \pm 1.1$ & $5.6 \pm 1.3$ \\
TLC\% of predicted & $62.0 \pm 13.5$ & $75.2 \pm 16.4$ & $89.6 \pm 11.4$ & $85 \pm 2.3$ \\
FEV 1 FVC\% & $84.1 \pm 7.4$ & $78.8 \pm 8.6$ & $79.7 \pm 7.8$ & $79 \pm 7.4$ \\
DLCO $\%$ of predicted & $46.4 \pm 17.6$ & $59.7 \pm 19.5$ & $76.3 \pm 18.8$ & $81 \pm 17.1$ \\
\hline
\end{tabular}

Mean values $\pm \mathrm{SD}$, or median values (25th-75th percentile).

IPF: idiopathic pulmonary fibrosis; NSIP: non-specific interstitial pneumonia; FVC: forced vital capacity; TLC: total lung capacity, DLCO\%: diffusing lung capacity for carbon monoxide.

Table 2. Metallic elements in exhaled breath condensate of patients with idiopathic pulmonary fibrosis (IPF), non-specific interstitial pneumonia (NSIP) or sarcoidosis, and controls.

\begin{tabular}{lllll}
\hline Metals $\left(\mu \mathrm{g} \mathrm{L}^{-1}\right)$ & $\operatorname{IPF}(n=19)$ & NSIP $(n=15)$ & Sarcoidosis $(n=22)$ & Controls $(n=33)$ \\
\hline $\mathrm{Al}$ & $1.8(0.72-2.50)$ & $1.6(1.2-3.3)$ & $1.6(1.2-2.08)$ & $1.2(0.60-2.35)$ \\
$\mathrm{Pb}$ & $0.04(\mathrm{ND}-0.13)$ & $0.03(\mathrm{ND}-0.09)$ & $0.04(\mathrm{ND}-0.1)$ & $0.02(0.008-0.055)$ \\
$\mathrm{Ni}$ & $0.40(0.3-0.6)^{*}$ & $0.5(0.3-0.8)^{*}$ & $0.40(0.31-0.6)^{*}$ & $0.20(0.08-0.40)$ \\
$\mathrm{Cr}$ & $0.05(0.03-0.20)^{*}$ & $0.1(0.03-1.1)^{*}$ & $0.07(0.04-0.28)^{*}$ & ND (ND-0.015) \\
$\mathrm{Si}$ & $66(38-140)^{*}$ & $87(59-146)^{*}$ & $59(41-92.5)^{*}$ & $19(0.5-47)$ \\
$\mathrm{Co}$ & ND (ND-0.008) & $0.01(\mathrm{ND}-0.01)$ & ND (ND-0.01) & $0.01(\mathrm{ND}-0.025)$ \\
$\mathrm{Ca}$ & $41(29-49)$ & $23(16-82)$ & $47(25-75.7)$ & $63(38-243)$ \\
$\mathrm{Zn}$ & $2.1(\mathrm{ND}-6.6)$ & $0.6(\mathrm{ND}-3.5)$ & $0.22(\mathrm{ND}-2.1)^{*}$ & $1.6(0.50-22)$ \\
$\mathrm{Fe}$ & $0.30(0.20-0.50)^{*}$ & $0.30(0.20-0.40)^{*}$ & $0.35(0.21-0.9)$ & $1.20(0.25-6.00)$ \\
$\mathrm{Cu}$ & $0.10(\mathrm{ND}-0.4)^{*}$ & $0.01(\mathrm{ND}-0.40)^{*}$ & $0.25(\mathrm{ND}-0.48)^{*}$ & $0.60(0.30-1.80)$ \\
$\mathrm{Se}$ & $\mathrm{ND}$ & ND (ND-0.05) & ND (ND-0.1 & $0.30(0.10-1.20)$ \\
$\mathrm{Mn}$ & $0.17(0.10-0.30)$ & $0.20(0.12-0.28)$ & $0.23(0.09-0.3)$ & $0.10(0.04-0.25)$ \\
$\mathrm{Mo}$ & $\mathrm{ND}(\mathrm{ND}-0.02)^{*}$ & $0.02(\mathrm{ND}-0.05)$ & $0.01(\mathrm{ND}-0.03)$ & $0.03(0.01-0.08)$ \\
\hline
\end{tabular}

Median values (25th-75th percentile); ND: not determinable.

${ }^{*} p<0.05$ versus controls.

the metallic elements are useful in distinguishing controls and ILD patients. A significance level of 0.05 was used for all of the statistical tests.

\section{Results}

We initially recruited 61 patients with IPF, NSIP or sarcoidosis attending Parma Hospital's Outpatient Clinic of Interstitial Lung Diseases, and 33 healthy controls who were all nonsmokers and not occupationally exposed to metals. However five patients were smokers (2/17 with NSIP and 3/25 with sarcoidosis patients) and were excluded from the analysis. As no differences were found between the ex-smokers and nonsmokers with different ILDs, we did not consider being an ex-smoker a confounding factor.

We performed some experiments with non-smokers (no 5) where EBC was collected before and after having smoked a single cigarette. These are the results on the most important metals related to smoking habits in the literature $(\mathrm{Pb}$, $\mathrm{Ni}, \mathrm{Cr}, \mathrm{Al}, \mathrm{Cd}$ ). $\mathrm{Cr}$ and $\mathrm{Cd}$ were always below LOD. $\mathrm{Pb}$ passed from 0.04 (range: $\mathrm{ND}-0.07$ ) to $0.04(0.02-0.08) \mu \mathrm{g} \mathrm{L}^{-1}$;
Ni passed from $0.21(0.09-0.30)$ to $0.20(0.15-0.32) \mu \mathrm{g} \mathrm{L}^{-1}$; Al passed from $1.8(0.7-2.2)$ to $1.7(1.5-2.3) \mu \mathrm{g} \mathrm{L}^{-1}$.

Table 1 shows the characteristics of the study subjects. The results of the lung function tests showed that the patients with IPF and NSIP had a reduced TLC compatible with restrictive ventilatory defect (TLC $<80 \%$ ), whereas the patients with sarcoidosis had normal spirometric and plethysmographic values. All of the patients had decreased DLCO \% values, but both DLCO\% and TLC were lower in the patients with IPF (median $46.4 \%$ and $3.8 \mathrm{~L}$ ) than in those with sarcoidosis $(76.3 \%$ and $5.4 \mathrm{~L})(p<0.001)$.

The volume of EBC did not differ between patients and controls and age was not correlated with EBC metallic values.

Table 2 shows the metallic and trace elements determined in the EBC samples. Some metals were below the LOD in more than 50\% of cases: Cd in all groups; Co and Se in all of the patients; and Mo in the IPF group. In these cases, a level of half the LOD was arbitrarily assumed.

The EBC levels of some of the metallic elements considered to be pneumotoxic $(\mathrm{Cr}, \mathrm{Ni}, \mathrm{Si})$ were higher in all patient groups than in the controls (figure 1), whereas those of 

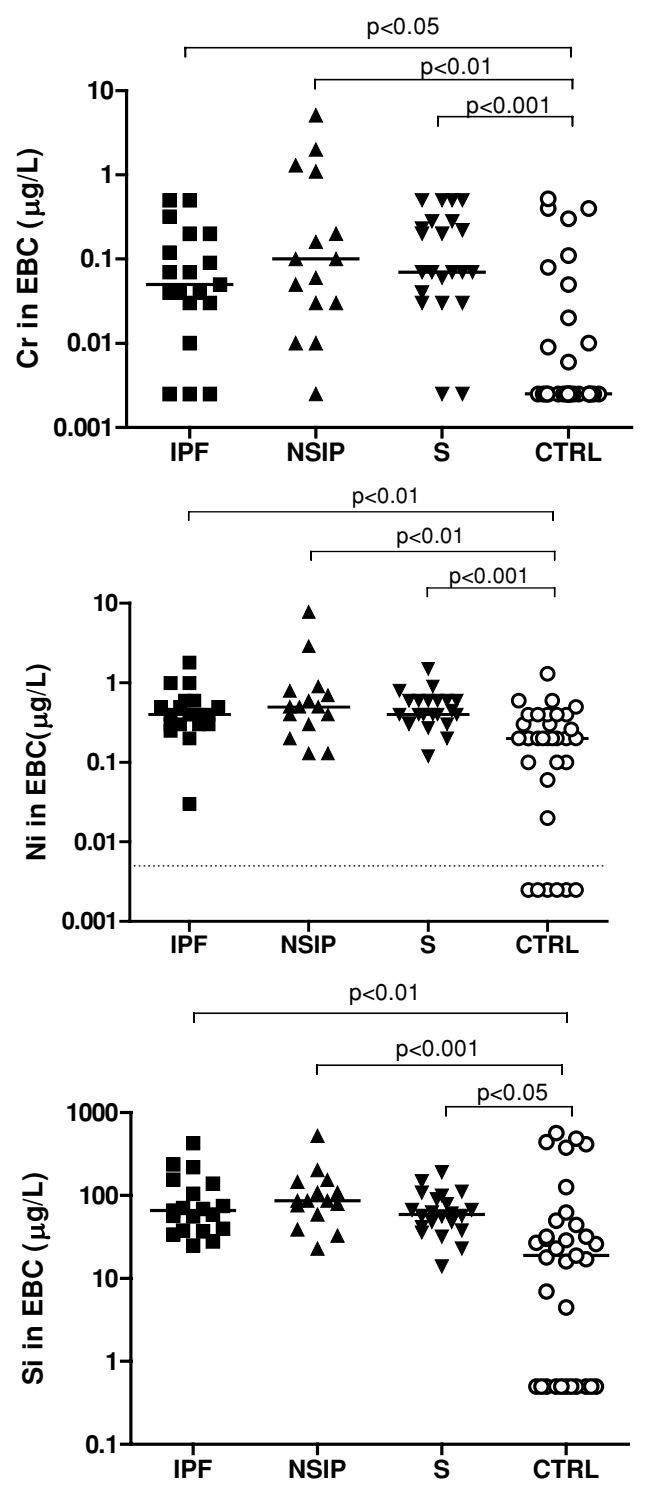

Figure 1. Ni, $\mathrm{Cr}$ and $\mathrm{Si}$ levels in $\mathrm{EBC}$ samples of patients with idiopathic pulmonary fibrosis (IPF), non-specific interstitial pneumonia (NSIP) or sarcoidosis (S), and controls (CTR)

Co were higher in the controls than in the IPF and sarcoidosis patients (table 2).

The transition elements that play an important role in the oxidant/anti-oxidant balance and are co-factors of various enzymes showed various trends: $\mathrm{Cu}$ and Se levels were higher in the controls than in all the patient groups (figure 2), and Fe levels were higher in the controls than in the IPF and NSIP patients (figure 2). Finally, Zn levels were higher in the controls than in the patients with sarcoidosis (table 2), and Mo levels were higher in the controls than in the IPF patients (table 2). The differences in the levels of the remaining metallic elements were not significant.

There was a positive correlation between EBC Fe levels and DLCO in the patients with sarcoidosis $(r=0.46 p<$ 0.05 ) (figure 3(A)), and between EBC Fe levels and TLC in the IPF patients $(r=0.53 ; p<0.05)$ (figure 3(B)). No other correlations were found between lung function parameters and EBC metallic elements.
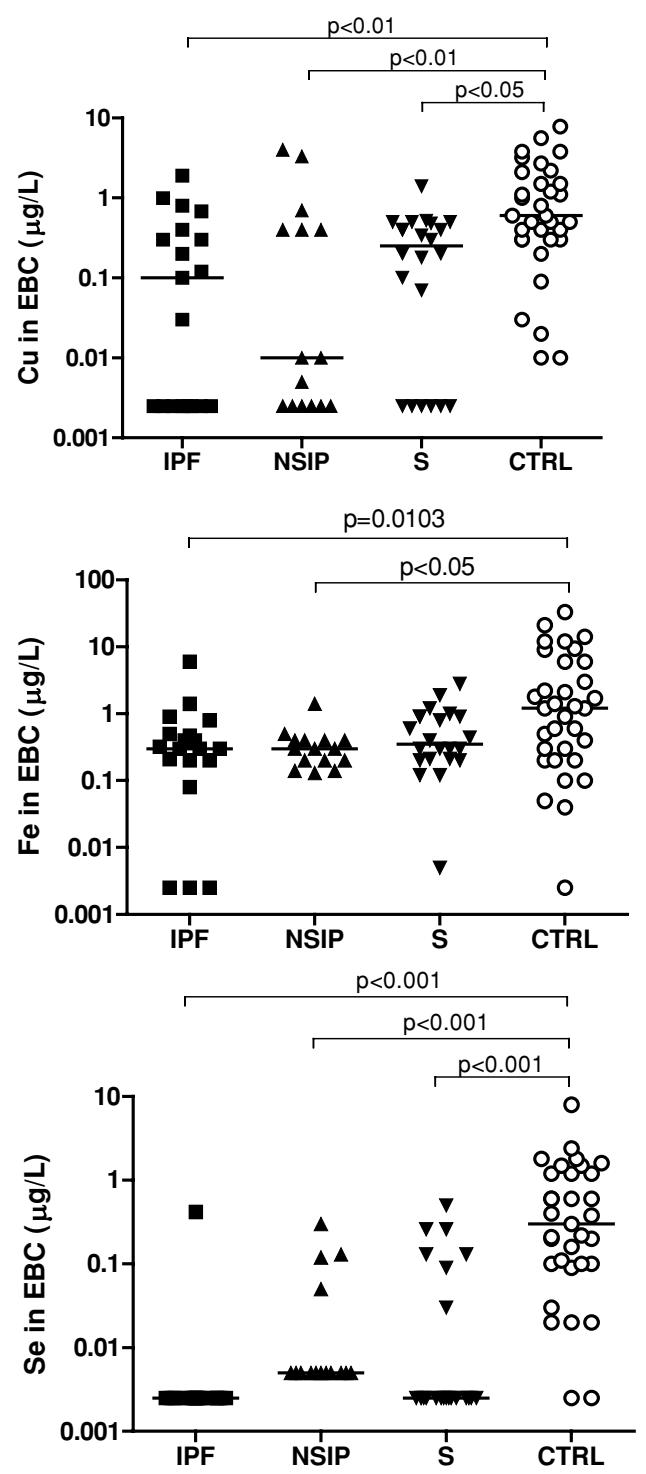

Figure 2. $\mathrm{Cu}, \mathrm{Fe}$ and $\mathrm{Se}$ levels in $\mathrm{EBC}$ samples of patients with idiopathic pulmonary fibrosis (IPF), non-specific interstitial pneumonia (NSIP) or sarcoidosis (S), and controls (CTRL).

A multinomial logistic regression model was first used to classify the IPF/NSIP patients, the patients with sarcoidosis and controls on the basis of the pattern of metallic elements in their EBC. Co, Mo, Ni, Cr, Si, Fe, Cu, Se and $\mathrm{Zn}$ were included in the model because of their significance in the comparisons; the other elements were excluded. $\mathrm{Zn}(p=0.035), \mathrm{Si}(p=$ $0.014), \mathrm{Ni}(p=0.002)$ and $\mathrm{Se}(p=0.009)$ distinguished the controls from the IPF/NSIP patients, and Co $(p=0.015), \mathrm{Ni}$ $(p=0.002)$ and $\mathrm{Se}(p=0.043)$ distinguished the controls from the patients with sarcoidosis (table 3(A)). However, the classification table (table 3(B)) showed that the controls were correctly classified in $87.9 \%$ of cases $(29 / 33)$, whereas there was an overlap between the sarcoidosis and IPF/NSIP groups in $63.6 \%$ of cases $(14 / 22)$.

The analysis was therefore repeated considering all of the ILDs together and using binary logistic regression (table 4). This model identified Co $(p=0.015)$, Zn $(p=0.029)$, Si $(p=0.026)$, Ni $(p=0.002)$ and $\mathrm{Se}(p=0.021)$ as 
Table 3. (A) Classification of cases by means of multinomial logistic regression analysis. The patients with IPF or NSIP were considered as a single group. (B) The significance of each metallic element estimated by means of multinomial logistic regression analysis, with controls as the reference category.

\begin{tabular}{lllcl}
\hline (A) & \multicolumn{4}{c}{ Predicted } \\
\hline Observed & IPF/NSIP & Sarcoidosis & Controls & Percent correct \\
IPF/NSIP & 28 & 3 & 3 & $82.4 \%$ \\
Sarcoidosis & 14 & 8 & 0 & $36.4 \%$ \\
Controls & 2 & 2 & 29 & $87.9 \%$
\end{tabular}

(B)

\begin{tabular}{|c|c|c|c|c|c|}
\hline \multicolumn{2}{|c|}{$\begin{array}{l}0=\mathrm{IPF} \text { and NSIP; } \\
1=\text { sarcoidosis } \\
2=\text { controls }^{\mathrm{a}}\end{array}$} & \multirow{2}{*}{$\begin{array}{l}\text { Significance } \\
0.303\end{array}$} & \multicolumn{2}{|c|}{$\begin{array}{l}0=\text { IPF and NSIP; } 1= \\
\text { sarcoidosis; } \\
2=\text { controls }^{\mathrm{a}}\end{array}$} & \multirow{2}{*}{$\begin{array}{l}\text { Significance } \\
0.246\end{array}$} \\
\hline \multirow[t]{10}{*}{0.00} & Intercept & & 1.00 & Intercept & \\
\hline & Co & 0.044 & & Co & 0.015 \\
\hline & Mo & 0.626 & & Mo & 0.171 \\
\hline & $\mathrm{Zn}$ & 0.035 & & $\mathrm{Zn}$ & 0.055 \\
\hline & $\mathrm{Cu}$ & 0.065 & & $\mathrm{Cu}$ & 0.061 \\
\hline & $\mathrm{Si}$ & 0.014 & & $\mathrm{Si}$ & 0.102 \\
\hline & $\mathrm{Fe}$ & 0.418 & & $\mathrm{Fe}$ & 0.653 \\
\hline & $\mathrm{Cr}$ & 0.765 & & $\mathrm{Cr}$ & 0.908 \\
\hline & $\mathrm{Ni}$ & 0.002 & & $\mathrm{Ni}$ & 0.002 \\
\hline & $\mathrm{Se}$ & 0.009 & & $\mathrm{Se}$ & 0.043 \\
\hline
\end{tabular}

a 2.00 is the reference category.
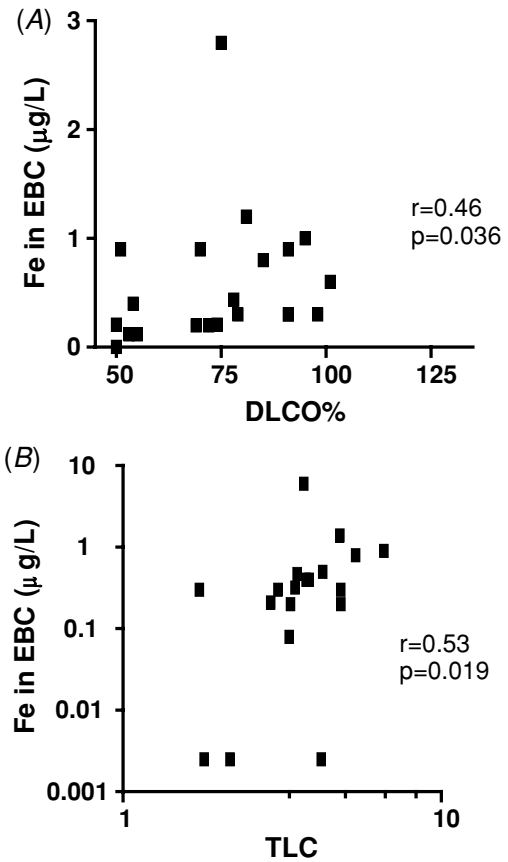

Figure 3. (A) Correlations between DLCO\% and Fe levels in EBC of patients with sarcoidosis. (B) Correlation between TLC values and Fe levels in EBC samples of patients with idiopathic pulmonary fibrosis.

discriminant metallic elements, and $\mathrm{Cu}$ was nearly significant $(p=0.056)$. The classification table showed that $96.4 \%$ of the ILD patients were correctly classified (54/56), and again $87.9 \%$ of the controls (29/33) (table 4 and figure 4$)$. When the significant metallic elements were considered separately, $\mathrm{Ni}$ showed the greatest sensitivity $(87.5 \%)$ and specificity $(63.6 \%)$.
Table 4. (A) Classification of cases by binary logistic regression analysis. The patients with IPF, NSIP or sarcoidosis were considered as a single group. (B) The significance of each metallic element estimated by binary logistic regression analysis.

\begin{tabular}{llll}
\hline (A) & \multicolumn{3}{c}{ Predicted } \\
\hline Observed & ILD & Controls & Percent correct \\
ILD & 54 & 2 & $96.4 \%$ \\
Controls & 4 & 29 & $87.9 \%$
\end{tabular}

(B)

\begin{tabular}{ll}
\hline $\begin{array}{l}0=\mathrm{IPF}, \mathrm{NSIP} \\
\text { and sarcoidosis; } \\
1=\text { controls }\end{array}$ & Significance \\
\hline $\mathrm{Co}$ & 0.015 \\
$\mathrm{Mo}$ & 0.381 \\
$\mathrm{Zn}$ & 0.029 \\
$\mathrm{Cu}$ & 0.056 \\
$\mathrm{Si}$ & 0.026 \\
$\mathrm{Fe}$ & 0.474 \\
$\mathrm{Cr}$ & 0.999 \\
$\mathrm{Ni}$ & 0.002 \\
$\mathrm{Se}$ & 0.021 \\
\hline
\end{tabular}

The probability of belonging to a given group calculated by means of logistic regression was also used as a discriminant variable in a ROC distinguishing controls and the ILD groups as a whole (figure 5). Although the area under the ROC was 0.978 (95\% CI 0.56-1) and therefore significantly different from 0.5 , a cut-off point of 0.407 maximized the sum of sensitivity and specificity: sensitivity was 0.964 (95\% CI 0.876-0.995) and specificity 0.909 (95\% CI 0.756-0.980).

Drug treatment for other ILD patients were constituted by oral corticosteroids alone (20 patients: 5 IPF, 9 NSIP 

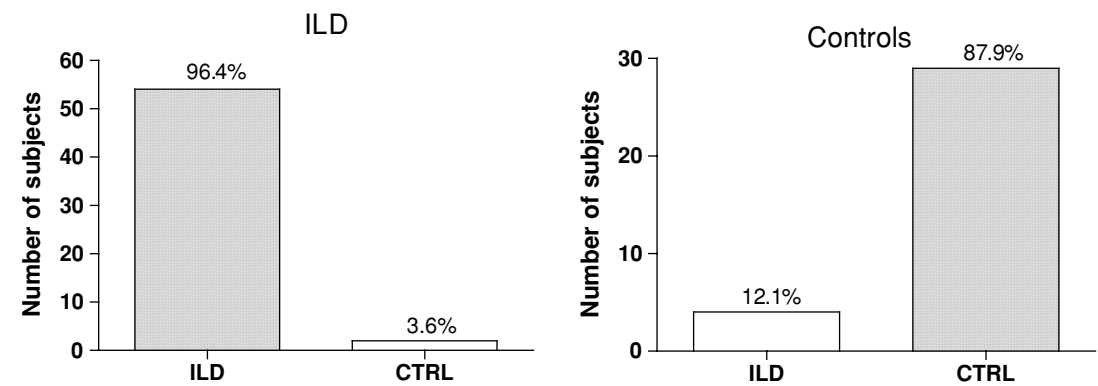

Figure 4. Classification of cases by means of binary logistic regression analysis.

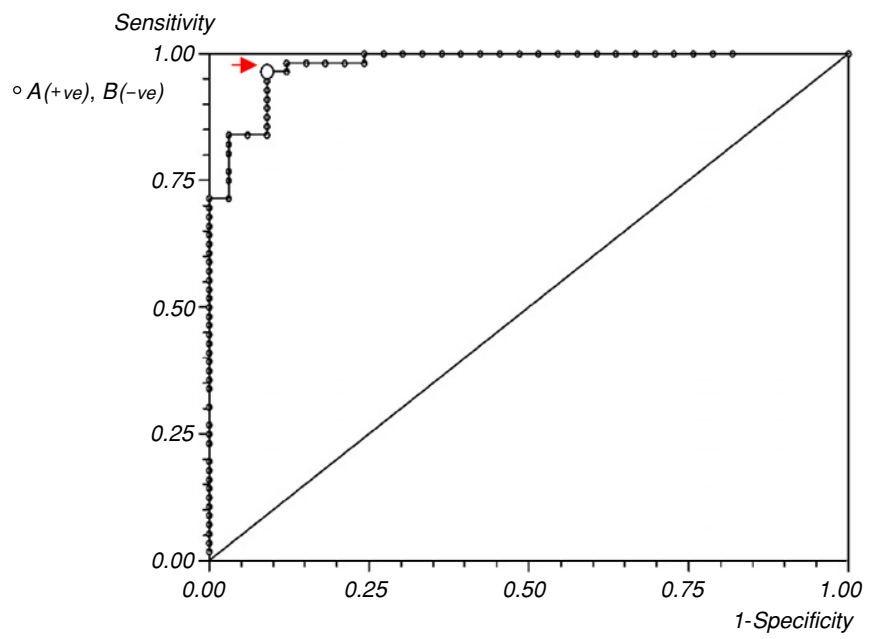

Figure 5. ROC curve. The probability of belonging to a given group (interstitial diseases or control) calculated by means of logistic regression was used as a discriminant variable in the ROC curve. The red arrow represents the cut-off point that maximized the sum of sensitivity and specificity

(This figure is in colour only in the electronic version)

and 6 sarcoidosis) or in association with immunosuppressive treatment (8 patients: 3 IPF, 4 NSIP and 1 sarcoidosis) or in combination with hydroxychloroquine sulfate (3 sarcoidosis); two patients were treated with pirfenidone (2 IPF) and two with $\mathrm{N}$-acetylcysteine (2 IPF). No differences in EBC metal levels were observed when patients were classified according to drug intake, nor differences were observed when ILD patients were classified according to each disease severity.

\section{Discussion}

The results of this study show that there are only small overall differences in the EBC levels of a number of metallic elements among patients with IPF, NSIP or sarcoidosis, and no pattern is capable of distinguishing them with a high degree of sensitivity and specificity. However, a pattern of pneumotoxic ( $\mathrm{Si}, \mathrm{Ni})$ and essential elements ( $\mathrm{Zn}, \mathrm{Se}$ and, perhaps $\mathrm{Cu}$ ) with the addition of Co distinguished the patients with ILDs from healthy nonsmokers with relatively high degrees of sensitivity (96.4\%) and specificity (90.9\%). The results were much more modest when the individual elements were considered separately, despite the significant between-group differences in their levels.
The EBC samples of all of the ILD patients contained higher levels $\mathrm{Ni}, \mathrm{Cr}$ and $\mathrm{Si}$ than those of the controls, and those of the patients with IPF or sarcoidosis had lower levels of Co. Furthermore, all of the ILD patients showed lower levels of $\mathrm{Cu}$ and $\mathrm{Se}$ than the controls, and the patients with IPF or NSIP had lower levels of Fe.

We have previously assessed the elemental composition of EBC in patients with chronic obstructive pulmonary disease (COPD) or asthma, as well as in healthy smokers and nonsmokers [21]. The COPD patients showed higher levels of $\mathrm{Al}, \mathrm{Pb}$ and $\mathrm{Cd}$ than the healthy non-smokers, and lower levels of $\mathrm{Cu}$ and $\mathrm{Fe}$, and the patients with asthma had lower levels of Fe than the healthy non-smokers and higher Ni levels than the healthy smokers. There were also differences between the smokers and ex-/non-smokers in the COPD group: the former had higher levels of $\mathrm{Pb}$ and $\mathrm{Cd}$, and in comparison with the healthy non-smokers, the latter had higher levels of $\mathrm{Pb}, \mathrm{Cd}$ and $\mathrm{Al}$. We therefore assumed that the increased levels of the three metallic elements in the COPD patients were probably related to cumulative long-term exposure to tobacco smoke ( $88 \%$ of the COPD patients were current or exsmokers) or environmental exposure to pneumotoxic metals, and that the lower levels of $\mathrm{Cu}$ and $\mathrm{Fe}$ due to the metal depletion involved in the anti-oxidant responsive element. As inflammation and oxidative stress are common in ILDs and other pulmonary diseases, it is not surprising that, like those with COPD or asthma in our previous study, the ILD patients in this study had lower levels of $\mathrm{Cu}$ and $\mathrm{Fe}$. However, ILDs have specific pathological mechanisms and histopathological features that may explain the difference in the EBC levels of some pneumotoxic metals.

Furthermore, the ILD patients in this study were all ex-smokers or non-smokers, and we did not observe any confounding effect of smoking on their EBC levels of metallic elements. Consequently, $\mathrm{Al}, \mathrm{Cd}$ and $\mathrm{Pb}$ were completely unaffected by disease status in comparison with the controls (Cd was almost always below the LOD). In contrast, the EBC levels of other pneumotoxic metals ( $\mathrm{Ni}, \mathrm{Cr}$ and $\mathrm{Si}$ ) were higher in the ILD patients, thus indicating that they were probably different from those of the COPD and asthmatic patients as a result of different exposure to tobacco smoke. Further studies are in progress in an attempt to identify different EBC patterns of pneumotoxic metallic elements in patients with different pulmonary diseases.

The fact that the levels of some metallic elements $(\mathrm{Ni}$, $\mathrm{Cr}$ and $\mathrm{Si}$ ) were higher in our ILD patients than in the 
healthy controls may be due to their greater persistence at the pulmonary level. Despite the differences between IPF, NSIP and sarcoidosis, interstitial fibrosis is common to all ILDs and could make the removal of metals difficult. Structural alterations in the pulmonary interstitium reduce gaseous exchange and this is reflected in the decreased DLCO levels typical of ILD (and also found in our patients). Moreover, these metals may be retained in the lungs for many years after exposure has ceased.

Furthermore, published data from mineral microanalyses of lung tissue or pulmonary lymph nodes in patients with ILD indicate that there is a possible association between IPF and mineral dust such as silica/silicates, $\mathrm{Al}$ and $\mathrm{Ni}$ [34-36], and this is partially in line with our results. In a case report about a young man with ILD, who was exposed for many years to metal dust as a grinder covering steel tools with hard metals, analysis of a lung biopsy performed 4 years after the exposure had ceased showed higher levels of $\mathrm{W}, \mathrm{Ta}, \mathrm{Co}, \mathrm{Cr}$ and $\mathrm{Ni}$ than those found in 17 control biopsies [37]. However, the data are difficult to interpret in terms of causality because of the lack of a clear and established etiology and, in our study, the difficulty in obtaining quantitative measures of dose and the duration of an exposure that occurred many years ago.

Chronic inflammation and the associated oxidative stress are important mechanisms in the pathogenesis of ILD [38]. We found that, in comparison with the controls, the ILD patients had lower EBC levels of some of the transition elements $(\mathrm{Cu}$, $\mathrm{Fe}$ and $\mathrm{Se}$ ) involved in the redox systems controlling oxidative stress. It is probable that the reduction in these trace elements was due to their pulmonary depletion as a result of chronic oxidative stress and inflammation [21].

The assessment of occupational exposure to metals in our patients was done with a questionnaire (commonly used in Italy to assess occupational exposure to metals), as biological monitoring would have been not possible as most of the patients were retired. We acknowledge that the questionnaire may have limitation, especially when previous and possible old exposures have to be assessed; this is why we proposed the EBC metal analysis as a new tool to assess lung metal burden in previously exposed patients.

To the best of our knowledge, there are no other studies of metals in the EBC of patients with ILD, but Bargagli et al [39] have recently assessed the concentrations of some metals in BAL samples taken from patients with sarcoidosis, IPF or Langerhan cell histiocytosis, and compared them with the levels observed in healthy (smoking and non-smoking) controls. The levels (given in micrograms per liter) varied widely but were one to two orders of magnitude higher than our EBC results, as can be expected because of the greater dilution of non-volatile substances in EBC in comparison with tissues, broncho-alveolar lining fluid and other biological fluids; however, they were lower than the factor of 100010000 supposed for the dilution of EBC as compared with blood. Unlike us, the authors found significantly lower levels of $\mathrm{Mn}$ in their patients than in the controls, and lower levels of both $\mathrm{Zn}$ and $\mathrm{Cr}$ in the patients with IPF, which they assumed to be due to oxidative stress or clearance mechanisms. EBC and BAL data are difficult to be compared, as correlations between biomarkers in the two matrixes are generally poor [40].
We also found that the EBC pattern of metallic elements, which was significantly different in the controls and ILD patients, distinguished the two groups with a relatively high degree of sensitivity (96.4\%) and specificity (90.9\%), though individual elements were much less diagnostic, despite the significant differences between groups in their levels.

One limitation of this study is the relatively small sample size, which is explained by the low prevalence of ILD in the general population. Given this low prevalence, it would seem to be more appropriate to use analyses of the elemental composition of EBC to rule out rather than confirm ILD in subjects with suspect symptoms. Therefore, our findings require validation in larger clinical studies. The findings of this study could be improved by evaluating other ILDs in order to verify whether there are any differences in the EBC levels of metallic elements that may reflect differences in pathological conditions that would be useful in distinguishing patients with similar diseases. Furthermore, due to still unknown mechanisms leading to EBC formation and possible environmental confounding factors, it is not possible to define reference values from healthy subjects; thus a pattern of relative changes rather than absolute concentration should be considered.

In conclusion, assessing the elemental composition of EBC in patients with different ILDs seems to provide useful information. We found higher levels of $\mathrm{Ni}, \mathrm{Cr}$ and $\mathrm{Si}$ in ILD patients than in controls, and lower levels of some trace elements involved in the oxidant/anti-oxidant balance; this depletion may be due to the oxidative stress and chronic inflammation characterizing ILDs. Furthermore, the pattern of some metallic elements seemed to be able to differentiate controls and patients.

The non-invasiveness of the EBC method makes it suitable for patients with pulmonary diseases, although further studies are required to confirm the usefulness of this approach and to better understand the underlying pathophysiological processes.

\section{Acknowledgments}

Massimo Corradi and Antonio Mutti designed the study. Matteo Goldoni performed statistical analysis. Olga Acampa, Elena Adami and Alberto Pesci recruited patients. Giuseppe de Palma and Pietro Apostoli performed metal analysis. All authors participated in the text writing and data discussion.

\section{References}

[1] King T E 2005 Clinical advances in the diagnosis and therapy of the interstitial lung diseases Am. J. Respir. Crit. Care Med. 172 268-79

[2] American Thoracic Society/European Respiratory Society 2002 International multidisciplinary consensus classification of the idiopathic interstitial pneumonias Am. J. Respir. Crit. Care Med. 165 277-304

[3] British Thoracic Society and Standards of Care Committee 1999 The diagnosis, assessment and treatment of diffuse parenchymal lung disease in adults Thorax 54 (Suppl 1) $\mathrm{S} 1-\mathrm{S} 30$ 
[4] Demedts $\mathrm{M}$ et al 2001 Interstitial lung diseases: an epidemiological overview Eur. Respir. J. 18 (Suppl 32) $2 \mathrm{~s}-16 \mathrm{~s}$

[5] Thomeer M J, Costabel U, Rizzato G, Poletti V and Demedts M 2001 Comparison of registries of interstitial lung diseases in three European countries Eur. Respir. J. 18 (Suppl. 32) 114s-8s

[6] Lynch J P, Ma Y L, Koss M N and White E S 2007 Pulmonary sarcoidosis Semin. Respir. Crit. Care Med. 28 53-74

[7] Judson M A 2008 Sarcoidosis: clinical presentation, diagnosis, and approach to treatment Am. J. Med. Sci. 335 26-33

[8] Verleden G M et al 2001 Genetic predisposition and pathogenetic mechanisms of interstitial lung diseases of unknown origin Eur. Respir. J. 18 (Suppl. 32) 17s-29s

[9] Steele M P and Brown K K 2007 Genetic predisposition to respiratory diseases: infiltrative lung diseases Respiration 74 601-8

[10] Taskar V and Coultas D 2008 Exposures and idiopathic lung disease Semin. Respir. Crit. Care Med. 29 670-9

[11] Taskar V S and Coultas D B 2006 Is idiopathic pulmonary fibrosis an environmental disease? Proc. Am. Thorac. Soc. $3293-8$

[12] Baumgartner K B, Samet J M, Stidley C A, Colby T V and Waldron J A 1997 Cigarette smoking: a risk factor for idiopathic pulmonary fibrosis Am. J. Respir. Crit. Care Med. $155242-8$

[13] Hubbard R, Lewis S, Richards K, Johnston I and Britton J 1996 Occupational exposure to metal or wood dust and aetiology of cryptogenic fibrosing alveolitis Lancet 347 284-9

[14] Baumgartner K B, Samet J M, Coultas D B, Stidley C A, Hunt W C, Colby T V and Waldron J A 2000 Occupational and environmental risk factors for idiopathic pulmonary fibrosis: a multicenter case-control study Am. J. Epidemiol. $152307-15$

[15] Miyake Y et al 2005 Occupational and environmental factors and idiopathic pulmonary fibrosis in Japan Ann. Occup. Hyg. 49 259-65

[16] Pinheiro G A, Antao V C, Wood J M and Wassel J T 2008 Occupational risk for idiopathic fibrosis mortality in the United States Int. J. Occup. Environ. Health 14 117-23

[17] ACCESS Research GroupNewman L S et al 2004 A case control etiologic study of sarcoidosis: environmental and occupational risk factors Am. J. Respir. Crit. Care Med. 170 1324-30

[18] Barnard J et al ACCESS Research Group 2005 Job and industry classifications associated with sarcoidosis in A Case-Control Etiologic Study of Sarcoidosis (ACCESS) J. Occup. Environ. Med. 47 226-34

[19] Kharitonov S A and Barnes P J 2006 Exhaled biomarkers Chest 130 1541-6

[20] Antczak A and Górski P 2002 Markers of pulmonary diseases in exhaled breath condensate Int. J. Occup. Med. Environ. Health 15 317-23

[21] Mutti A, Corradi M, Goldoni M, Vettori M V, Bernard A and Apostoli P 2006 Exhaled metallic elements and serum pneumoproteins in asymptomatic smokers and patients with COPD or asthma Chest 129 1288-97

[22] Maniscalco M, De Laurentiis G, Pentella C, Mormile M, Sanduzzi A, Carratù P and Sofia M 2006 Exhaled breath condensate as matrix for toluene detection: a preliminary study Biomarkers 11 233-40

[23] Goldoni M, Catalani S, De Palma G, Manini P, Acampa O, Corradi M, Bergonzi R, Apostoli P and Mutti A 2004 Exhaled breath condensate as a suitable matrix to assess lung dose and effects in workers exposed to cobalt and tungsten Environ. Health Perspect. 112 1293-8
[24] Goldoni M, Caglieri A, Poli D, Vettori M V, Corradi M, Apostoli P and Mutti A 2006 Determination of hexavalent chromium in exhaled breath condensate and environmental air among chrome plating workers Anal. Chim. Acta $562229-35$

[25] Caglieri A, Goldoni M, Acampa O, Andreoli R, Vettori M V, Corradi M, Apostoli P and Mutti A 2006 The effect of inhaled chromium on different exhaled breath condensate biomarkers among chrome-plating workers Environ. Health Perspect. 114 542-6

[26] Mutti A and Corradi M 2006 Recent developments in human biomonitoring: non-invasive assessment of target tissue dose and effects of pneumotoxic metals Med. Lav. 97 199-206

[27] Mastruzzo C, Crimi N and Vancheri C 2002 Role of oxidative stress in pulmonary fibrosis Monaldi Arch. Chest Dis. 57 $173-6$

[28] Nemery B et al 2001 Interstitial lung disease induced by exogenous agents: factors governing susceptibility Eur. Respir. J. 18 (Suppl 32) 30s-42s

[29] Boots A W, Drent M, Swennen E L, Moonen H J, Bast A and Haenen G R 2009 Antioxidant status associated with inflammation in sarcoidosis: a potential role for antioxidants Respir. Med. 103 364-72

[30] Travis W D et al 2008 Idiopathic nonspecific interstitial pneumonia: report of an American thoracic society project Am. J. Respir. Crit. Care Med. 177 1338-47

[31] ATS/ERS/WASOG Committee 1999 Statement on sarcoidosis Am. J. Respir. Crit. Care Med. $160736-55$

[32] Costabel U 2001 Sarcoidosis: clinical update Eur. Respir. J. 18 (Suppl. 32) 56s-68s

[33] Corradi M, Acampa O, Goldoni M, Andreoli R, Milton D, Sama S R, Rosiello R, de Palma G, Apostoli P and Mutti A 2009 Metallic elements in exhaled breath condensate and serum of patients with exacerbation of chronic obstructive pulmonary disease Metallomics $1339-45$

[34] Monsó E, Tura J M, Marsal M, Morell F, Pujadas J and Morera J 1990 Mineralogical microanalysis of idiopathic pulmonary fibrosis Arch. Environ. Health 45 185-8

[35] Kitamura H, Ichinose S, Hosoya T, Ando T, Ikushima S, Oritsu M and Takemura T 2007 Inhalation of inorganic particles as a risk factor for idiopathic pulmonary fibrosis-elemental microanalysis of pulmonary lymph nodes obtained at autopsy cases Pathol. Res. Pract. $203575-85$

[36] Siegesmund K A, Funahashi A and Pinter K 1974 Identification of metals in lung from a patient with interstitial pneumonia Arch. Environ. Health 28 345-9

[37] Rizzato G, Lo Cicero S, Barberis M, Torre M, Pietra R and Sabbioni E 1986 Trace of metal exposure in hard metal lung disease Chest 90 101-6

[38] Thannickal V J, Toews G B, White E S, Lynch J P and Martinez F J 2004 Mechanism of pulmonary fibrosis Annu. Rev. Med. 55 395-417

[39] Bargagli E, Monaci F, Bianchi N, Bucci C and Rottoli P 2008 Analysis of trace elements in bronchoalveolar lavage of patients with diffuse lung diseases Biol. Trace Elem. Res. 124 225-35

[40] Corradi M, Pignatti P, Brunetti G, Goldoni M, Caglieri A, Nava S, Moscato G and Balbi B 2008 Comparison between exhaled and bronchoalveolar lavage levels of hydrogen peroxide in patients with diffuse interstitial lung diseases Acta Biomed. 79 (Suppl 1) 73-8 